\section{Report backs whistleblower}

\section{Washington}

THE US Department of Energy (DOE) has sided with a metallurgist at one of its research laboratories who claims that he was hounded out of his job at Argonne National Laboratory after repeatedly raising questions about faulty and misleading data on an experimental nuclear reactor programme.

In a report made public on 2 April, the DOE's Office of Nuclear Safety (ONS) sided with James A. Smith, who says that fundamental errors were being made and published in work on a breeder reactor programme known as the Integral Fast Reactor (IFR). Argonne, which is 45 miles west of Chicago, is operated for DOE by the University of Chicago.

The 122-page ONS report also agreed with Smith's claim that he was threatened with the loss of his job after writing a memorandum suggesting that laboratory procedures to detect errors in data need to be improved. Smith resigned his position as an experimenter in August 1990 after being suspended. He admits that he is not interested in returning to the Argonne reactor, which is located at the Idaho National Engineering Laboratory.

Argonne strongly disputed the report from the ONS and says that Smith was discharged for not doing his job. Officials say that Smith became obsessed with the desire to refute every aspect of a fellow scientist's work, leaving him with little time to perform his own duties.

Smith's actual scientific concerns, which related to the melting points of the elements used in reactor fuel assemblies, seemed secondary to those that related to the scientific atmosphere of the laboratory. Smith said several of his colleagues told him he should stop worrying about the quality of work at the laboratory and consider his job as a way to earn a decent salary and live in a nice location.

But Smith rejected their advice. "Ididn't get a Ph.D. in metallurgy to go into some high-tech yuppie welfare programme," he says.

The DOE said that it did not find any evidence of fraudulent intent on the part of Argonne personnel, but that some work had been published or disseminated that was misleading. It said that the laboratory has a policy not to retract, correct or qualify research even when errors or serious questions about its validity are uncovered. The ONS report also found that Smith described accurately a scientific culture at the laboratory that was "oversensitive to internal politics, real or imagined slights and other social considerations." That culture, it says, undermines peer review and adherence to scientific accuracy.

A spokesman for the laboratory denies emphatically that Argonne has any such policy with respect to refereed journals but that the material in question appeared in an in-house newsletter. "It's the written equivalent of walking down the hall and talking to your colleague", says the spokesman. Retractions or corrections are made at the discretion of the author and the editors of the newsletter, he added.

Argonne also denies that it intentionally published any misleading material, and asserts that it stands solidly behind peer review and adherence to scientific principles and accuracy. In its defense, the laboratory pointed to an outside evaluation of the technical issues that Smith raised.

The technical panel, convened after the ONS completed its report last December, concluded that none of the concerns that Smith raised threatened the safety of the laboratory principally because IFR, a metal-fuelled, liquid sodium-cooled 'fast' reactor, is at least 20 years away from production. But the DOE report said that the kinds of errors and practices that Smith identified could be repeated in other programmes at the laboratory.

Smith also questioned the independence of the technical evaluation committee. He pointed out that two of the panel's three members also sit on a special advisory panel to the reactor project that reports to the University of Chicago's board of governors. He says that the committee ignored the "gross blunders" that he raised.

"It's a case of the foxes guarding the chicken coop," Smith says of the technical panel review. "I'm shocked that the head of a national laboratory would even accept such a report, let alone tell people it vindicates his laboratory."

A spokesman for Argonne concedes that such a conflict-of-interest might exist "if someone had a vested interest in doing so". But he defends their presence on the evaluation committee by saying that it amounts to only a tiny amount of their professional duties and that the pool of experts in the field is small. It would not be prudent of them to avoid potential or real problems, he adds.

In spite of its disagreement with DOE on Smith's case, Argonne has agreed to implement the recommendations in the ONS report. They include developing an explicit policy of correcting known errors in its publications and issuing appropriate caveats when questions about its research are raised. The laboratory was also ordered to train its personnel to follow accepted principles of peer review that include how to resolve disputes between scientists. Employees will also be taught to recognize and respect those activities in which a whistleblower can be engaged without fear of retaliation.

David Kramer
China drives forward Beijing

ONCE China was a country that praised manual labour above brain work. Not any more. Last month the city government of Zhuhai in South China's Guangdong Province awarded an Audi automobile, an apartment and hundreds of thousands of Yuan (5.5 to the US dollar) to each one of a group of scientists for their outstanding contributions to their country's economic development.

Chinese intellectuals have complained for years about their low pay, poor living conditions and lack of social respect. But the program in Zhuhai, which is expected to continue indefinitely, marks an end to that situation. With its emergence as a global trading partner, China is looking for ways to encourage researchers to turn their ideas into products.

Putting a price tag on scientific progress is not easy, of course. The Zhuhai awards have raised questions about the value of those who engage in basic research. Should those whose work leads to commercial products be paid more than those whose achievements are mainly intellectual? Such ideas may seem far-fetched in a country that once put equality above all other civic principles, but increasingly they reflect what government officials are trying to accomplish.

You Qin Li

\section{Australia steps up}

\section{Sydney}

Australian engineers and scientists who work at large companies will receive salary increases of as much as $\mathbf{3 5}$ per cent this year under a ruling by the government commission that sets wages for a large portion of the country's labour force. The decision by the Industrial Relations Commission is viewed as a fundamental realignment of the pay rates for technical workers, in keeping with the government's desire to strengthen the country's research capacity and make science more attractive to students and others entering the labour force.

Under the new rates, the minimum starting salary for an engineer will rise by 35 per cent, to US\$21,470, and the pay of an engineer with four years' experience will increase by 29 per cent, to \$US26,430. The increase will affect about 25 per cent of the country's estimated 25,000 professionals whose employers are subject to the commission's ruling. Scientists and engineers at small companies negotiate their own salaries, which are frequently higher than the levels set by the commission.

Last year, academics throughout the country received a one-time salary increase of 16 per cent, and in 1990 government scientists received a similar increase. Both increases are supplemented by cost-of-living rises tied to the annual rate of inflation, now running at 4 per cent. Mark Lawson 